\title{
Diplomática y e-Diplomática: Pasado y futuro de la validación documental
}

Antonio Sánchez González

Universidad de Huelva (España)

Diego de la Prada Espina

Jano Archivos y Gestión S.L. (España) 



\title{
Diplomática y e-Diplomática: Pasado y futuro de la validación documental
}

\section{Diplomatic and e-Diplomatic: Past and future of the documentary validation}

\author{
Antonio Sánchez González \\ Universidad de Huelva (España) \\ antonio.sanchez@dhis2.uhu.es \\ Diego de la Prada Espina \\ Jano Archivos y Gestión S.L. (España) \\ janodoc3@gmail.com
}

Fecha de recepción: 29 de septiembre de 2019

Fecha de aceptación: 26 de diciembre de 2021

\section{Resumen}

La tesis planteada en el presente artículo mantiene la plena validez del metadato como elemento de validación de los documentos en los nuevos soportes y formatos digitales actuales, del mismo modo que la Diplomática -en cuanto a ciencia del documento- se servía, como hoy, de unos elementos de validación documental que los hacían y hacen auténticos e indubitados en soportes físicos como el pergamino o el papel. De ahí que tracemos aquí una breve evolución del sistema de validación documental a partir de la Edad Media, para demostrar que el documento considerado auténtico era lo que decía ser, con el fin de poner en conexión esos tradicionales elementos de validación con los elementos actuales, a través de los metadatos, con idéntica funcionalidad de garantizar la integridad y fiabilidad de los modernos documentos digitales. Para ello, nos acercamos primeramente a los documentos en soporte físico a través del análisis de sus suscripciones, signos, monogramas, ruedas, signaturas y sellos. Posteriormente, como contribución a lo que podíamos denominar e-Diplomática, valoramos las formas digitales de validación, que se produce a través de los metadatos de la gestión de los e-documentos, 
acercándonos al origen de su legitimidad como elementos que avalan que sean auténticos, disponibles y fiables.

Palabras clave: e-Diplomática; Documento físico; Documento digital; Validación documental; Metadatos; Evidencias electrónico-jurídicas; Firma electrónica.

\begin{abstract}
The thesis proposed in this article maintains the full validity of metadata as an element of validation of documents in the new digital media and formats of today, in the same way that Diplomacy -as far as the science of the documentused, as today, elements of documentary validation that made them and make them authentic and indubitable in physical supports such as parchment or paper. This is why we trace here a brief evolution of the document validation system from the Middle Ages, to demonstrate that the document considered authentic was what it claimed to be, in order to connect these traditional elements of validation with current elements, through metadata, with the same functionality of guaranteeing the integrity and reliability of modern digital documents. To this end, we first approach documents on physical support through the analysis of their subscriptions, signs, monograms, wheels, signatures and seals. Subsequently, as a contribution to what we could call e-Diplomatic, we valued the digital forms of validation, which are produced through the metadata of the management of e-documents, approaching the origin of their legitimacy as elements that guarantee that they are authentic, available and reliable.
\end{abstract}

Keywords: e-Diplomatic; Physical document; Digital document; Documentary validation; Metadata; Electronic-legal evidence; Electronic signature.

\title{
1. INTRODUGGIÓN
}

A la Diplomática, con respecto al documento objeto de su estudio, lo que más le ha interesado a lo largo del tiempo es analizarlo y enjuiciarlo críticamente para averiguar su autenticidad, o la búsqueda de lo que se consideraba el texto "justo" como garantía de derechos.

En la Antigüedad, la autenticidad del documento era consecuencia de su preservación en el lugar destinado a ese fin (templo, palacio del gobernador, archivo...). De hecho, documentos falsos eran depositados en tales oficinas para darles carácter de auténticos. Al percatarse de esa práctica, los legisladores introducen algunas reglas para reconocer y al mismo tiempo evitar este tipo de abusos, caso del Corpus Iuris Civilis de Justiniano y, más tarde, de algunas decretales pontificias.

En el siglo XVII la polémica entre jesuitas y benedictinos poniendo en duda la autenticidad de determinados documentos medievales origina la edición, en 1681, de la célebre obra de Jean Mabillon De re Diplomatica libri VI, en la que se establecen las reglas fundamentales de la crítica textual, que han sido adoptadas y adaptadas por los 
diplomatistas posteriores hasta nuestros días, para garantizar la autenticidad de los documentos mediante una serie de elementos de validación.

Pero, con el cambio de la tecnología mecánica a la digital y la llegada del documento electrónico (e-Doc.), tales prácticas de validación de los documentos en soporte tradicional han tenido que adaptarse también a esos nuevos soportes mediante los metadatos, ya que estos, además de identificar, describir, gestionar y permitir su accesibilidad, sirven para autentificar a estos documentos.

De ahí que hayamos acuñado el término e-Diplomática ${ }^{1}$ para referirnos a la ciencia que aborda el estudio del documento digital prestando especial atención a su génesis, evolución, tradición y conservación, no solo con el fin de demostrar su autenticidad sino también su valor como fuente. Pues, como es fácilmente entendible, el e-Doc. busca "en sus nuevas formalidades las mismas antiguas características de autenticidad, fiabilidad, integridad y permanencia del tradicional documento escrito", al seguir siendo - como en épocas pasadas - un instrumento de permanencia de hechos y actos de la gestión administrativa (Redondo, 2010, p. 392).

Para poder servir de prueba, un documento debe poseer tales características, como define la Guía para la Gestión de Registros Electrónicos del Consejo Internacional de Archivos (ICA, 2011a, pp. 22 y 25):

- autenticidad, entendida como "la persistencia a lo largo del tiempo de las características originales del documento respecto al contexto, la estructura y el contenido", es decir, que un documento sea lo que pretende ser.

- fiabilidad, entendida como la capacidad del propio documento para "servir de prueba fidedigna", aspecto que hace referencia a la autoridad y veracidad de los documentos como prueba.

- integridad, entendida como el hecho de que un documento esté completo y no haya sido alterado.

- permanencia, entendida como el documento que puede utilizarse a efectos de justificación a lo largo del tiempo.

A lo que le añadimos la disponibilidad, entendida como la capacidad de localizar, recuperar, presentar e interpretar un documento, llegado el caso (Norma UNEISO 15489-1: 7.2.3 y 7.2.4).

1 Así lo hemos hecho en los programas de nuestra asignatura de Diplomática del grado en Historia, en la Facultad de Humanidades de la Universidad de Huelva, desde hace varios cursos académicos. 


\section{LA AUTENTICIDAD DEL DOGUMENTO}

La Diplomática, como ciencia que estudia la elaboración de los documentos, debe juzgar su autenticidad y apreciar la calidad de los textos, De hecho, la primera labor del diplomatista tradicionalmente ha sido enjuiciar la autenticidad del documento, tanto la diplomática como la jurídica e incluso la histórica.

En cuanto a la autenticidad diplomática, que discierne los documentos verdaderos de las falsificaciones, son verdaderos aquellos que son lo que aparentan ser, esto es, que han seguido un proceso de génesis, expedición y validación correcto y con la finalidad para la que se expidieron. Por el contrario, se considera falso diplomáticamente el documento que "quiere parecer lo que no es", en palabras de Bresslau (1889-1931, I, p. 7).

Para detectar indicios de falsificación en un documento el diplomatista debe examinar sus caracteres externos e internos al objeto de identificar posibles contradicciones con las prácticas usuales en la elaboración documental de cada época (Canellas, 1991). En cuanto a los caracteres internos habrá que analizar las posibles contradicciones sobre los formulismos empleados normalmente para esos documentos y respecto a las personas o entidades que participaron tanto en la acción jurídica (actio) como en la escrituración (conscriptio).

En la Edad Media fue la Curia Pontificia la encargada de establecer las primeras normas para regular y determinar la autenticidad documental. Concretamente con el papa Inocencio III (1198-1216) se regularon determinados formalismos en la redacción y transcripción de los documentos expedidos por la cancillería papal y sobre el método que había que seguirse para examinar y corroborar la autenticidad de los documentos, con medidas tales como determinar si el sello era auténtico o estaba falsificado, si el hilo que lo sujetaba era legítimo o si el sello se había desatado de su documento primitivo para unirlo al falso; también había que observar si en el texto había raspaduras que hubieren alterado la naturaleza del documento. Se estaba creando así las bases del análisis diplomático de la autenticidad documental en los inicios del siglo XIII.

Aun así, la labor de los peritos de la cancillería pontificia, en realidad, solo era aplicable a documentos contemporáneos suyos, resultando ineficaz para determinar la autenticidad de diplomas antiguos, puesto que se carecía de conocimientos históricos suficientes sobre las prácticas documentales anteriores. Fue en el Renacimiento cuando vino a suplirse, si bien parcialmente, esta limitación gracias al eruditismo histórico de los humanistas desde fechas muy tempranas.

En la conocida como "guerra diplomática" del siglo XVII, el jesuita holandés Papenbroek incluyó una introducción al Acta Sanctorum (1675) en la que, tras exponer su método para analizar la autenticidad de los documentos, concluía tachando de falsificaciones al grueso de los diplomas merovingios franceses que custodiaba la abadía maurista de Saint Denís en París. La respuesta benedictina, encomendada a 
Jean Mabillon, generó la publicación en 1681 de su De re diplomatica libri VI, en la que se nominaba a la disciplina y la definía como dedicada a analizar los documentos antiguos y emitir sobre ellos un juicio acerca de su autenticidad o falsedad. Para Mabillon -y esta sería una concepción llamada a perdurar-, la vinculación jurídico-institucional del documento primaba sobre cualquier otro aspecto, su escriturado o su dimensión histórica, lingüística, etc.

Así, Oliver Legipont (1759) definía los documentos diplomáticos a mediados del XVIII como armas legales para defender los derechos y facultades, y para perpetuar legal y públicamente la memoria de los hechos acaecidos.

La autenticidad histórica, por su parte, hace referencia a la veracidad del contenido del documento, pudiéndose dar el caso de un documento diplomáticamente auténtico e íntegramente falso históricamente; o a la inversa, es decir, puede ser absolutamente histórico (su contenido es verdadero) pero falso desde el punto de vista diplomático.

Respecto a la autenticidad jurídica, por último, hace referencia a que el documento ha sido realizado conforme a los requisitos establecidos y que, por tanto, es válido como prueba pública de autenticidad, fundamentalmente porque ha intervenido un representante de la autoridad pública que garantiza que es fehaciente.

En síntesis, tal como tipificara A. Boüard (1929, I), auténtico es el documento que emitió su autor en la fecha que en él se precisa de forma directa o indirecta; es fehaciente si está revestido de las formalidades legales para hacer fe sin prueba de juicio; verdadero cuando informa sobre la realidad de los hechos y falso cuando enmascara esa realidad ${ }^{2}$.

Y en cuanto a la autenticidad del e-Doc., el Manual de Documentos Electrónicos afirma que, para evidenciar que es auténtico hay que demostrar que fue producido o recibido en el momento que se dice producido o recibido, que el proceso que lo produjo - humano o automático - fue el que sostenemos que se dio, que el documento forma verdaderamente parte del sistema del que se afirma formar parte, y que sus contenidos no han sido alterados de ningún modo desde que pasó a formar parte del sistema de archivo (ICA, 2011b, p. 61).

\section{VALIDAGIÓN DE DOCUMENTOS EN SOPORTES FÍSICOS}

Para que un documento sea auténtico necesita tener una serie de elementos validativos.

2 Sobre los documentos falsos, véase Ouy, 1961. 
3.1. Formas de validación documental en la Diplomática tradicional

La validación de los documentos en soporte tradicional resulta de las acciones por las que reciben sus signos o marcas de autenticidad, apuestas sobre el mundum o puesta en limpio del escrito. Tiene, pues, una doble manifestación:

a) La de los signos y suscripciones o firmas con que se cerraba el texto documental para darle fuerza de derecho.

b) La del distintivo o contraseña que se añadía al documento para ratificar esa misma fuerza y, sobre todo, como garantía de autenticidad consistente, por lo general, en un sello o en un dibujo especial. El sello se aplicaba, de ordinario, a los documentos públicos; el dibujo a los privados.

El pormenor de estos sistemas de validación es el que sigue.

\subsubsection{Suscripción}

La legislación medieval exigía para la validación de los documentos la prueba testifical, es decir, la presencia y suscripción de las partes (autor jurídico, escribano, etc.) y testigos.

Las suscripciones son las fórmulas por las que dichas partes marcan la participación que han tenido en el acto jurídico y escrito manifestando su voluntad personal, su consentimiento o su presencia. Sinónimo de firma, al principio son autógrafas y, más adelante, será el "rogatario" - como agente de la escrituración- quien las suscriba (Linage, 1970 y Mendo, 1997).

Lo más común, por tanto, es que contenga el nombre de la persona o personas que han participado en la elaboración del documento, además de una locución en la que se consigna el acto jurídico documentado seguida del anuncio de la intervención personal y el signo de la cruz u otros signos de diferente envergadura gráfica (Fraenkel, 1992, pp. 38-39).

Precisamente la principal función de la suscripción era garantizar la autenticidad del escrito, es decir, servir como elemento de validación (Giry, 1975, pp. 591-592).

\subsubsection{Signo}

Es el dibujo o marca personal que se inserta por las partes intervinientes en la elaboración del documento o los testigos de un acto jurídico. Al principio suele ser una simple cruz autógrafa (signum crucis) que se ponía al lado del nombre ${ }^{3}$.

3 Con el tiempo, se adopta la cruz como firma, en caso de personas analfabetas. 
Esta cruz se convertirá en algo testimonial por lo que desaparece, sustituyéndose por la palabra "signum", que puede también aparecer abreviada como "S.". De ahí que podamos encontrar el nombre de la persona y el "signum" detrás, todo esto escrito de su puño y letra por el notario para validar las escrituras que autorizaba con todas las garantías legales que convertían estos documentos en instrumentos públicos, como símbolo de que se cumplían los requisitos legales (Valls Subirá, 1962).

Así el signo (Fig. 1) se convirtió en un elemento singular, característico y casi exclusivo del notariado español (Bono, 1990).

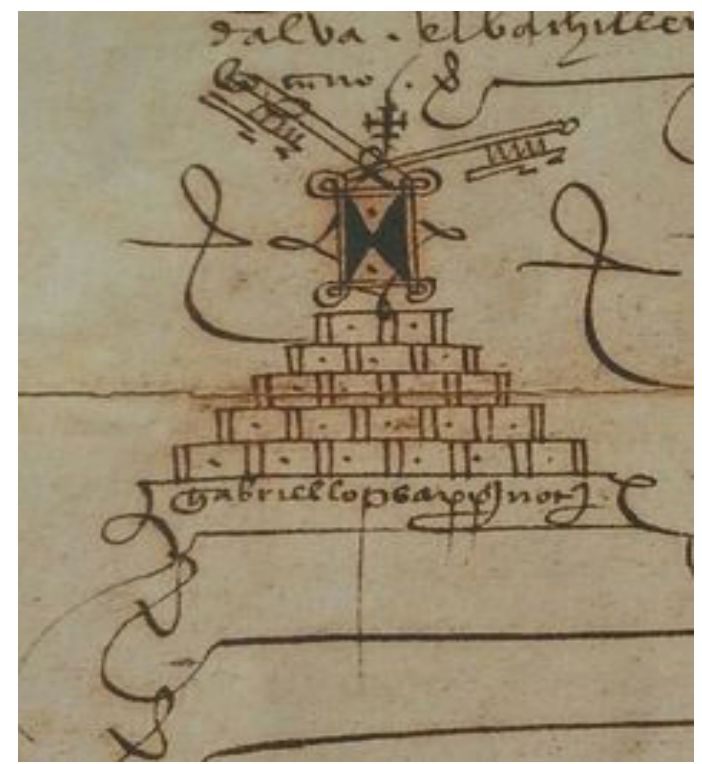

Figura 1. Signo notarial del siglo XVII. Fuente: https://i.pinimg.com/originals/5d/5e/30/5d5e305d05b44eb2b595ae56aff33f88.jpg

\subsubsection{Monograma}

Es una abreviatura, formada normalmente por letras entrelazadas, que sirve para validar el documento. Puede constar de una serie de letras dispuestas según un diseño más o menos geométrico que representa un nombre o parte del mismo, y los hay de diferente tipología (axial, lineal, circular, etc.).

En el Occidente medieval ocupa el lugar del signum de los soberanos (Fig. 2 izq.) y, en tal caso, está formado por las letras de su nombre o por una o varias palabras (Eisenlohr, 1994) .

4 En ocasiones, además de las iniciales del soberano, podía acompañar la corona real. 

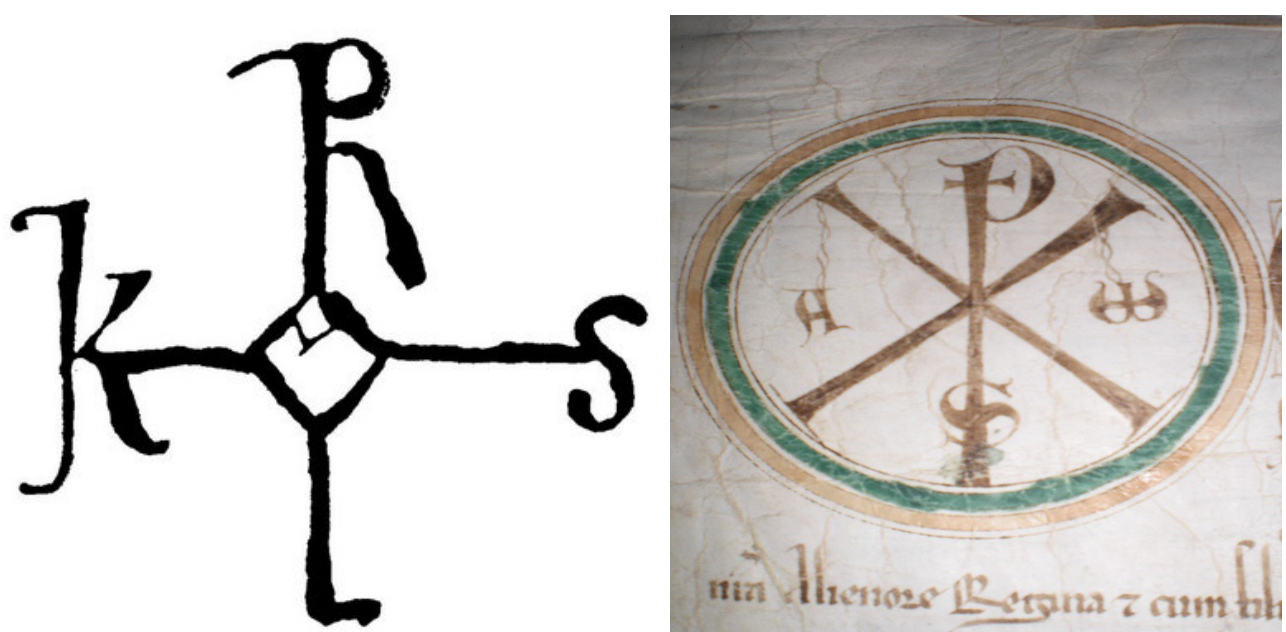

Figura 2. Monograma de Carlomagno y crismón

Otro monograma característico de los documentos medievales era el crismón, formado por la superposición de las dos primeras letras del nombre de Cristo en griego -Cristo -, ji (X) y ro (P), a las que se añadía las letras A y $\Omega$ (esta generalmente en su grafía minúscula) flanqueadas o suspendidas de los brazos superiores de la ji o del vástago horizontal para dar un matiz de eternidad (Fig. 2 der.). Además de símbolo de Cristo, el crismón es emblema de victoria, tanto militar como espiritual -triunfo de la fe y triunfo sobre la muerte-, por lo que era habitual encontrarlo asociado también a contextos funerarios (García, 2010).

\subsubsection{Rota o rueda}

Con origen en documentos pontificios del siglo XI, la rota era la marca o signo de validación e identificación en forma de rueda utilizada en época medieval por diversas autoridades en documentos oficiales, normalmente solemnes, para servir como signo validativo y de autentificación a lo escriturado (Riesco, 2003:371).

Se coloca en la parte final o al pie de ciertos documentos relevantes para darles un suplemento de validez, a la par que de solemnidad (Francisco Olmos, 2017), caso por ejemplo de los privilegios pontificios y de algunas cancillerías reales como la normanda de Sicilia.

También la rota es característica del célebre privilegio "rodado" hispánico medieval, tipo documental más solemne de cuantos expedían los soberanos castellanos-leoneses en sus cancillerías, que apareció en el reinado de Alfonso VIII y se extinguió con los Reyes Católicos nada más iniciarse el siglo XVI. Era llamado así, precisamente, por llevar el signo real (signum regis) inscrito en un círculo -signo 
rodado- (Fig. 3), bien dibujado o iluminado (Pardo, 1999, Sánchez, 2012 y García y Sánchez, 2020).

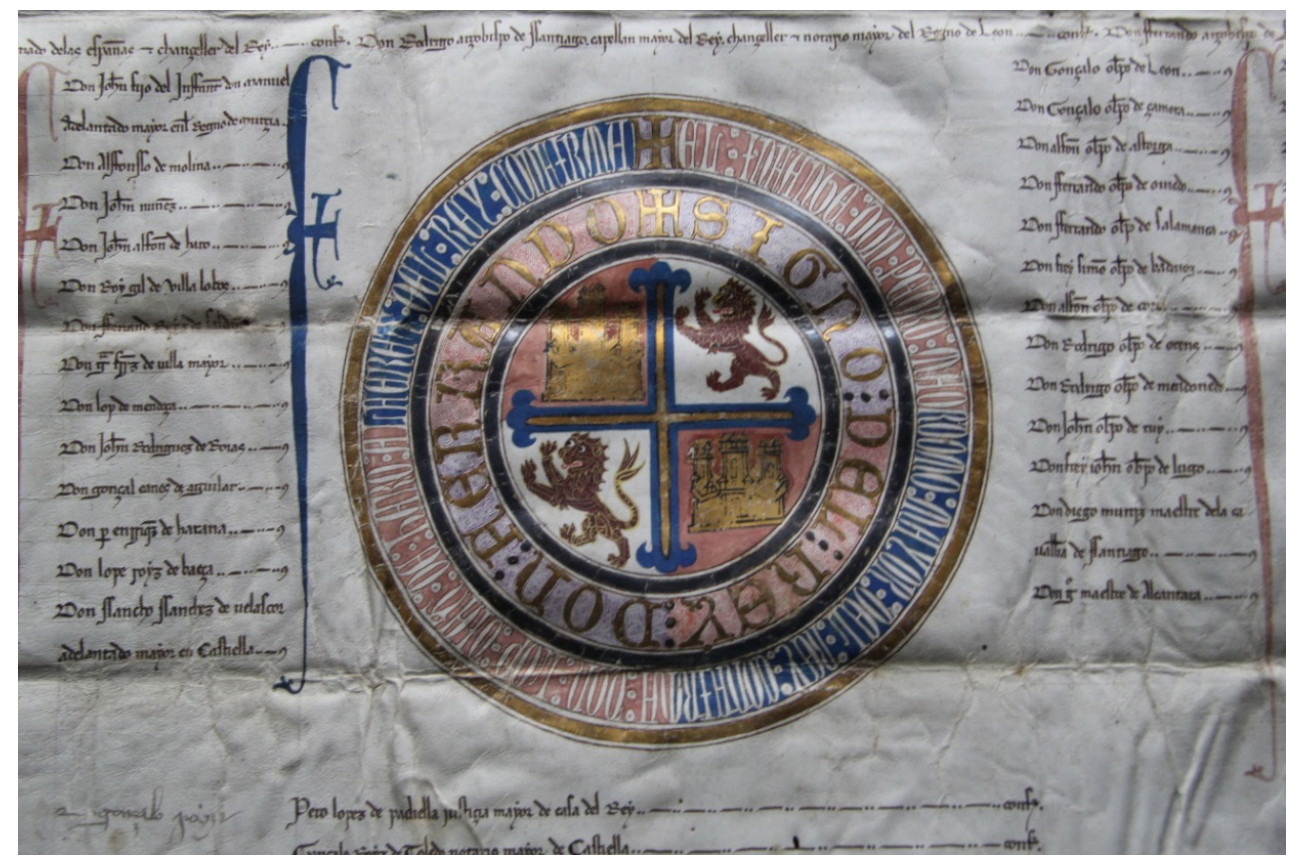

Figura 3. Signo rodado de Fernando IV (1310). Fuente: Archivo Ducal de Medinaceli, Privilegios rodados, $\mathrm{n}^{\circ} 23$

\subsubsection{Signatura}

Se compone por el nombre de la persona y la rúbrica. El nombre puede ser autógrafo o puesto por el notario (Fraenkel, 1992).

A partir siglo XIV este tipo de signatura suele ser autógrafa (firma), tanto por parte de las autoridades como de particulares.

En documentos reales hispanos (Álvarez Ceruela, 1957) es habitual que los moz narcas firmen expresando su título: "Yo, el Rey", "Yo, la Reyna" (Fig. 4). 


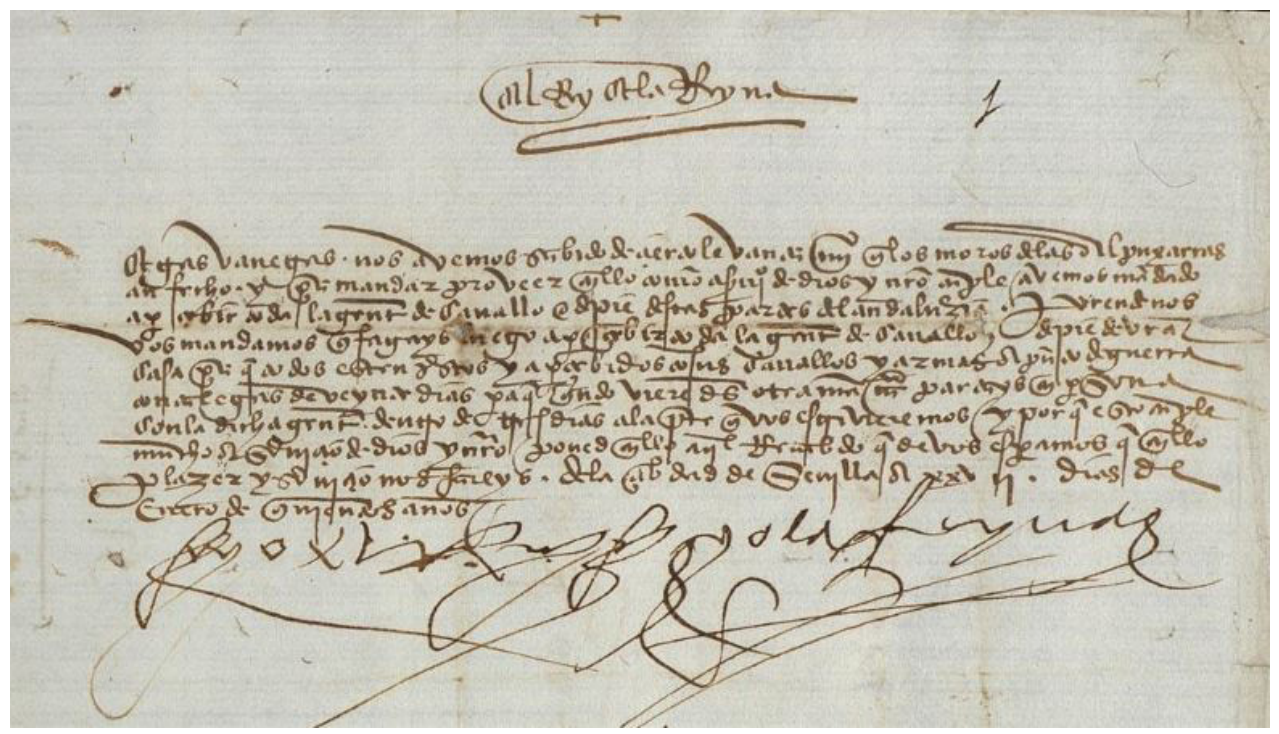

Figura 4. Real cédula de los Reyes Católicos con la suscripción autógrafa de los soberanos (1500). Fuente: Archivo Hco. Nobleza, Luque, caja 1, doc. 30

\subsubsection{Sello}

El sello es la impronta o imagen obtenida sobre un soporte maleable por la presión de una matriz grabada con los signos distintivos de una persona física o jurídica para testimoniar la voluntad de intervención de su dueño. La aposición del sello confiere al contenido del documento mayor garantía de autenticidad (Bascapé, 19691984, Kittel, 1970, Pastoureau, 1981, Laurent, 1985, Menéndez Pidal, 1993 y 2018 o Carmona, 1996).

De ahí que la matriz del sello se confiara a determinados personajes de la cancillería o escribanía (guardasello, canciller, notario, etc.) que la conservan para aponer el sello en los documentos.

De muy diversas tipologías -metálicos (fundamentalmente de plomo, pero también de oro y otros metales), cerados, pendientes, de placa (Arribas Arranz, 1941), etc.-, el sello constituía el elemento esencial y último de la validación documental.

El campo del sello puede presentar imágenes muy diversas, obviamente haciendo siempre mención del titular. Unas imágenes son figurativas, como las mayestáticas (titular sentado en trono y con los emblemas de su poder en la mano), ecuestres (montado a caballo), pedestres o estantes (de pie), iconográficos o hagiográficos (figuras religiosas) o efigiados (retrato del titular). Y otros sellos son no figurativos, con motivos heráldicos (blasones), topográficos (paisajes de ciudades o lugares), monu- 
mentales (edificios), los parlantes (figuras alegóricas, por ejemplo, una granada para indicar Granada), de escritura (solo texto, sin imágenes), fantásticos (con figuras mitológicas o inventadas) y profesionales (con herramientas u otros instrumentos laborales alusivos a la corporación que lo emite). Entre los sellos efigiados se encuentran los característicos de los documentos pontificios con los rostros de San Pedro y San Pablo (Fig. 5).
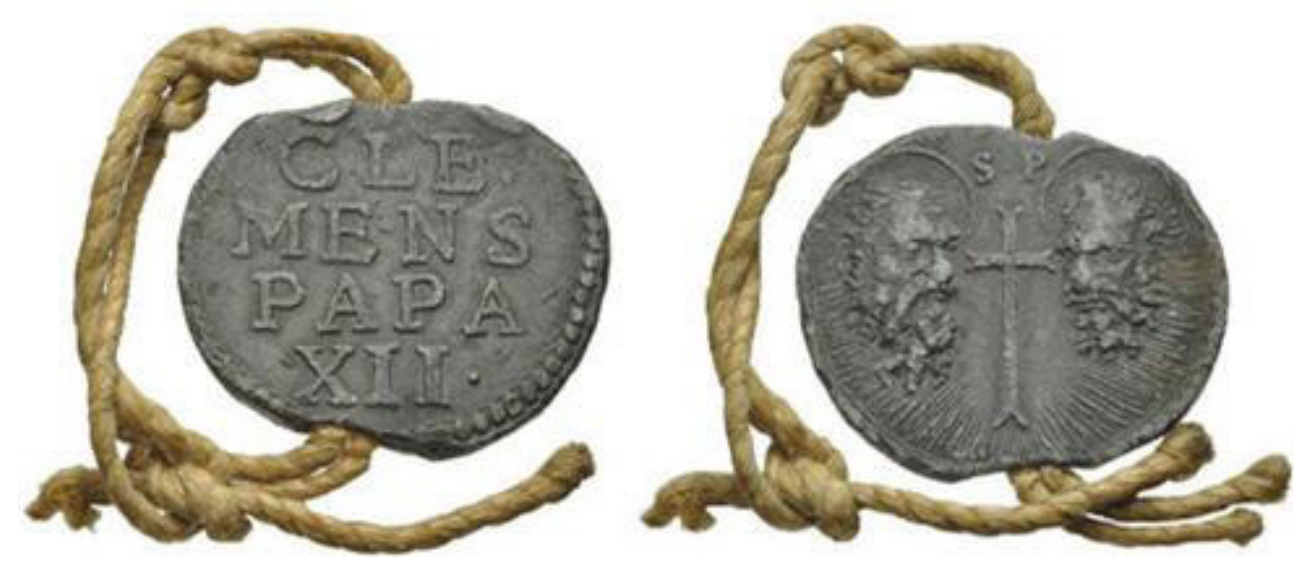

Figura 5. Reverso y anverso del sello de plomo del papa Clemente XII (1735). Fuente: https://2img.net/h/s24.postimg.cc/vcpf3z5hh/bulla.jpg

En el siglo XVII se introdujo el papel sellado en España para cualquier instrumento público, por pragmática real de 15 de diciembre de 1636, con el fin de evitar falsificaciones. A modo de póliza, en la parte superior del documento a la izquierda aparece el sello real seguido de una frase estampillada indicando el impuesto de timbre exigido. A la larga este papel sellado ha servido para recaudar dinero para el Estado, más quizás que para evitar falsificaciones (Pérez-Aínsua, 2014).

\subsubsection{Otras fórmulas de validación}

Otros elementos de validación del documento son las listas de testigos (Fichtenau, 1979) o de confirmantes (Caruana, 1955), las "leyendas partidas" de cartas quirógrafas (Martín López, 95-1994 y Galende, 1996), así como representaciones figurativas (Rück, 1996 y Casado, 1997), distintas marcas de cancillerías y signos fiscales. 
Diplomática y e-Diplomática...- A. Sánchez González y D. de la Prada Espina

\section{DEFINICIÓN Y FUNGIONALIDADES DE LOS METADATOS DE LOS E-DOCS}

Con la entrada de la informática en la creación y gestión de los documentos y el cambio del soporte papel al entorno electrónico, los elementos de validación de los e-Docs. han cambiado radicalmente ya que, en la actualidad, con estos documentos generados en entornos digitales se ha producido una evolución que acarrea pérdidas y al mismo tiempo enriquecimientos con respecto a los documentos tradicionales.

Las pérdidas se concretan, sobre todo, en las herramientas físicas necesarias para la elaboración de los documentos, caso del papel y en menor medida del pergamino, las tintas e instrumentos de escribir manuales y mecánicos que han desaparecido en los documentos electrónicos. Sin embargo, como enriquecimientos, se incorporan el software, hardware, plataformas, algoritmos y metadatos que tienen su participación en la validación documental dela nueva e-Diplomática (véanse Díaz, 2007 y Bustos, 2018).

El nuevo entorno de trabajo surgido con este cambio crea a priori muchos desafíos sobre estos nuevos documentos, muchos de ellos conocidos, entre los que vamos a señalar los siguientes:

1. Facilidad de reproducción, con la posibilidad de que no se puedan diferenciar los originales múltiples de las copias de los originales.

2. Facilidad de manipulación, de modo que las modificaciones y cambios realizados sobre los documentos no son apreciadas a simple vista.

3. Dificultad para identificar al autor o autores de los documentos, con la complejidad añadida de que en algunos casos entre los autores puede haber uno o varios softwares.

4. Dificultad para definir la fecha del documento de creación, con su fecha real de creación, o de refrendo, o modificaciones y adendas.

5. Dificultad para identificar el hardware sobre el que se elaboró el documento.

6. Dificultad para identificar la versión del software original en el que se realizó.

7. Dificultad para migrarlo a versiones posteriores para posibilitar su acceso y empleo sin que pierdan su validez legal y fuerza jurídica.

La Resolución de 19/7/2011 de la Secretaría de Estado para la Función Pública, por la que se aprueba la Norma Técnica de Interoperabilidad (NTI) de Documento Electrónico, en su apartado III (BOE 182/2011, p. 87095), recoge estas partes de un e-Doc.:

- Datos e información contenida en el documento.

- En su caso, la firma electrónica.

- Los metadatos del e-Doc. 
Estos metadatos necesarios para la gestión de los e-Docs. han sido definidos como datos que dan al documento contenido, contexto y estructura desde su creación o incorporación (R.D. 4/2010, BOE 25/2010, p. 8154) y le dota de autenticidad, integridad y disponibilidad (Gómez Flores, 2015). Diversas instancias han mostrado un interés en definir los esquemas de metadatos que se usan en la gestión de los e-Docs. En el caso español, se definió un Esquema de Metadatos para la Gestión del Documento Electrónico (EMGDE) en el mismo R.D. 4/2010 (arts. 22-23) ${ }^{5}$ y, para los metadatos, la necesidad de establecer valores, propiedades, referencias y relaciones, para poder por medio de ellos disponer de documentos auténticos, fiables, íntegros y disponibles, conservables a largo plazo.

El presente esquema bebe en las directrices del Esquema Nacional de Seguridad, y principalmente en las normas ISO 23081-1 y 23081-2. Con respecto a la ISO 230811 , es de especial interés su punto 4 en cuanto dice que la gestión de los metadatos es inseparable a la gestión de los documentos, ya que los metadatos precisamente nos informan del contexto, contenido y estructura en que son creados los documentos (Incorporados), gestionados (Confeccionados, Tramitados) y conservados, así como sobre las fechas de adquisición por el sistema de gestión documental (o fecha de adquisición del documento), fechas en la que se producen trámites y modificaciones sobre los mismos, e incluso fechas previstas de eliminación de estos documentos. Los metadatos posibilitan la clasificación, acceso y disposición de los e-Docs. dentro de uno o varios dominios, permitiendo, en consecuencia, la acumulación de información en la vida del propio e-Doc. debido a la intervención de los diversos actores que intervienen en su confección y trámite.

\section{1. ¿Cómo es posible que funcionen estos metadatos?}

Se acepta que un Sistema de Gestión Documental (SGD) se define y aprueba por la dirección de la entidad, con valores, estructuras y reglas de los metadatos empleados y, más concretamente, un EMGDE que se adapte a la Política de Gestión de los Documentos. Existe una amplia literatura al respecto, tanto internacional (UNEISO 15489, 23081, familia de las 30300) como nacional (protocolo MOREq).

El referido R.D. 2010/4 aprueba el Esquema Nacional de Interoperabilidad de las Administraciones Electrónicas y desarrolla las NTI. Si nos detenemos en la Guía de Aplicación de la NTI de la Gestión de los Documentos Electrónicos ${ }^{6}$, su apartado 5 especifica que debe haber previamente definida una Política de Gestión Documental y que, en dicha política, se establecen valores y criterios de los documentos para que sean auténticos, disponibles y fiables, siendo esta política sancionada al más alto

5 BOE 25/2010: p. 8149-8150. Editado por el Ministerio de Política Territorial y Función Pública - Secretaría de Estado de la Función Pública en 2016.

6 Editada por el Ministerio de Hacienda y Administraciones Públicas - Secretaría General Técnica en 2016 la segunda edición. 
nivel de la organización. Según dicho apartado se deberá contemplar en dicha política estos aspectos:

- La aplicación de los criterios, métodos de trabajo y de conducta reconocidos, según lo establecido en la NTI de Catálogo de Estándares (Resolución de 28/6/2012 de la Secretaría de Estado para las Administraciones Públicas7).

- Las organizaciones han de garantizar la disponibilidad e integridad de los metadatos de sus e-Doc. manteniendo las relaciones de cada documento y sus metadatos (VII.1 de la Resolución).

- La implementación de metadatos de gestión de e-Doc. será diseñada por las organizaciones en base a sus necesidades, criterios y normativa específica (VII.2).

- Los metadatos de gestión de e-Doc. se articularán en esquemas de metadatos conforme a las necesidades de cada entidad (VII.3).

- El esquema de metadatos incluirá los metadatos mínimos obligatorios de los documentos (VII.4).

La política de Gestión de los e-Docs. establece que es el EMGDE el que define los metadatos, recogiéndose en la Guía de Aplicación de la NTI del Documento Electrónico, en su apartado 4, que los metadatos son un componente de pleno derecho del e-Doc., al definirlo como el elemento que le "proporciona contexto al contenido, estructura y firma... contribuyendo al valor probatorio de éste a lo largo del tiempo" como evidencia electrónica de las actividades y procedimientos ${ }^{8}$.

Se contempla en el punto 5 de la citada Guía de Aplicación de la NTI de la Política de Gestión de Documentos Electrónicos (PGDE) que, en virtud de las necesidades de cada organización, la dirección de las mismas tiene la responsabilidad del diseño e implementación de sus metadatos para la gestión de los e-Docs. Y en su punto 8 se desarrollan los requisitos que deben cumplir estos documentos con la asignación de dichos metadatos, los cuales a su vez deben hacer posible que:

- Puedan probar que son genuinos los documentos.

- Sean exactos y se pueda confiar en ellos.

- Permanezcan completos e inalterados.

7 BOE 178/2012: p. 53779.

8 4.1.26.III de la e-EMGDE v2.0, p. 16. Con la validación de una firma electrónica se comprueba la identidad del firmante, la integridad del documento firmado y la validez temporal del certificado utilizado. 
Cuadro I. Contexto de la Política de gestión de documentos en la organización. Fuente: Guía de Aplicación de la NTI de Política de Gestión de Documentos Electrónicos, p. 21

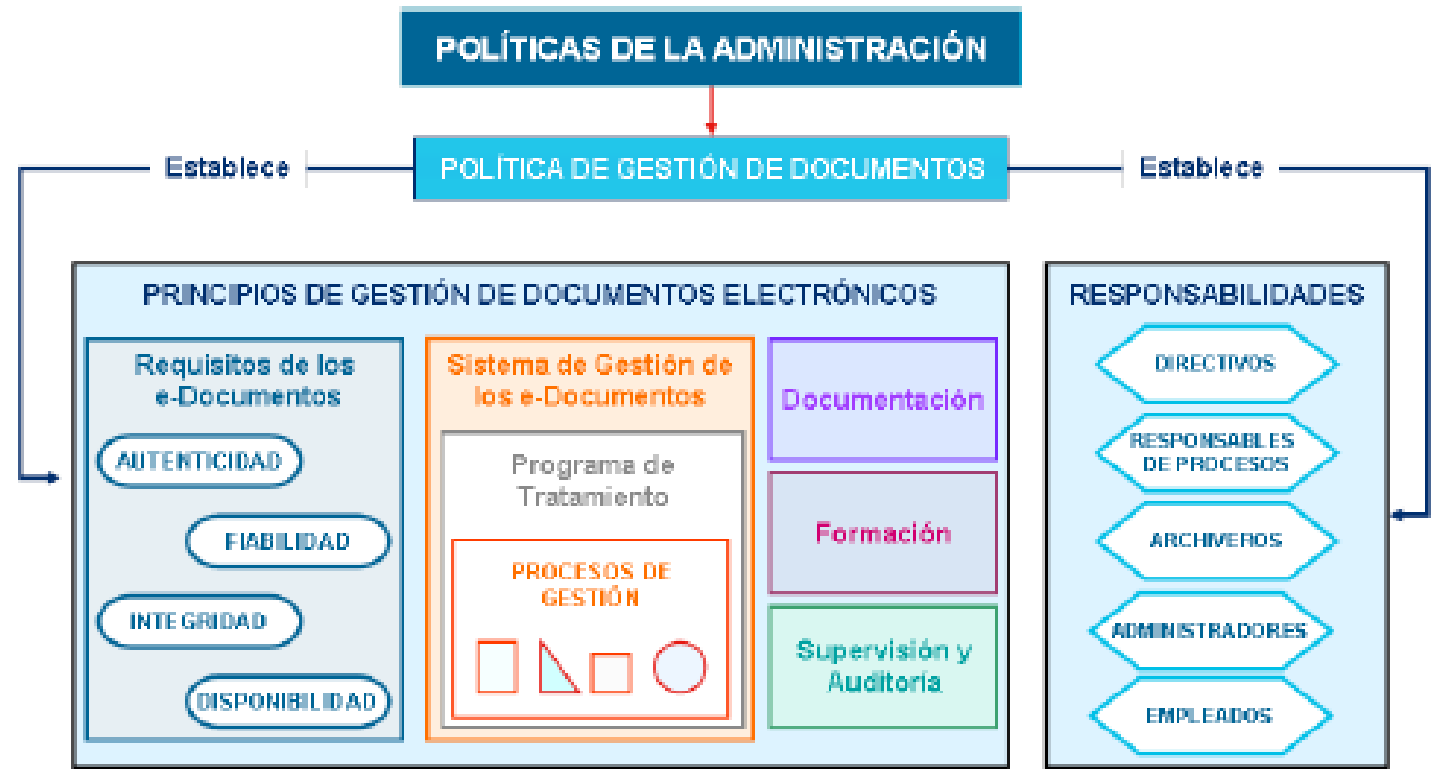

- Se mantengan seguros frente al acceso, la alteración o el borrado no autorizados.

- Se puedan encontrar, recuperar y leer.

- Estén relacionados con otros documentos pertinentes.

Concretamente, con la descripción de los documentos electrónicos mediante la incorporación de metadatos, se permite:

- Asegurar que se registra en los documentos la información contextual adecuada a los procesos y actuaciones.

- Ayudar a descubrir y recuperar documentos mediante la aplicación de vocabularios controlados, esquemas de valores y otros esquemas descriptivos normalizados.

- Controlar el acceso a los documentos, señalando en el momento de su creación e incorporación al sistema su categoría de seguridad o legal, o cualquier otra advertencia acerca de su conservación y uso.

- Facilitar el acceso a los documentos o su transferencia entre organizaciones cuando cambian las responsabilidades funcionales o de custodia. 
- Reducir el riesgo de acceso no autorizado o uso fraudulento de los documentos.

- Hacer posible la ejecución de las acciones dictaminadas sobre la documentación.

- Asegurar que no se pierden los documentos esenciales cuando se implantan nuevos sistemas.

- Ayudar a planificar la migración de datos y otras necesidades de conservación.

- Proporcionar una referencia para evaluar la calidad de la gestión de documentos dentro y entre organizaciones, a efectos de auditoría y control.

- Integrar de manera eficaz la información acerca de documentos electrónicos y documentos analógicos en los sistemas de control intelectual y en los instrumentos de recuperación.

Precisamente, como desarrollo del EMGDE, se definen las características de los metadatos como elementos que posibilitan que los documentos electrónicos sean auténticos, fiables y que estén disponibles. Estas características responden a la necesidad de contextualizar las relaciones que se producen por las distintas entidades, y hacen que los metadatos nos remitan a que cada documento es siempre único, original e irrepetible. El propio EMGDE reconoce que los documentos se producen en un contexto en el que participan varias entidades:

1. El Documento: "Información estructurada en cualquier formato creada, recibida y mantenida como evidencia por una organización o persona en cumplimiento de obligaciones legales o para actuaciones de gestión".

2. El Agente: Institución, órgano, persona o dispositivo responsable e involucrado en la creación, producción, custodia y gestión de los documentos.

3. La Actividad: Función marco, concreta, actividad y acción que ejerce una responsabilidad o competencia asignada a una unidad agente.

4. La Regulación: Marco normativo de la actividad y los requisitos para la gestión de los e-Doc.

5. La Relación: "Asociación entre dos o más entidades que tiene relevancia en un contexto de gestión y/o de gestión de documentos" Pueden ser de procedencia (Creación y uso del e-Doc.) y de evento de gestión (Proceso u operación).

Las relaciones nos ayudarán a dejar constancia del contexto en el que se generan los documentos, y permitirán describir eventos que se realizan sobre los mismos y sus vinculaciones sobre las distintas entidades. Las características de la lógica interna de los metadatos quedan reflejadas en el punto 3.1. del EMGDE, a saber: 
Cuadro II. Cobertura de los metadatos para la gestión de documentos electrónicos. Fuente: e-EMGDE-v2.0, p. 12

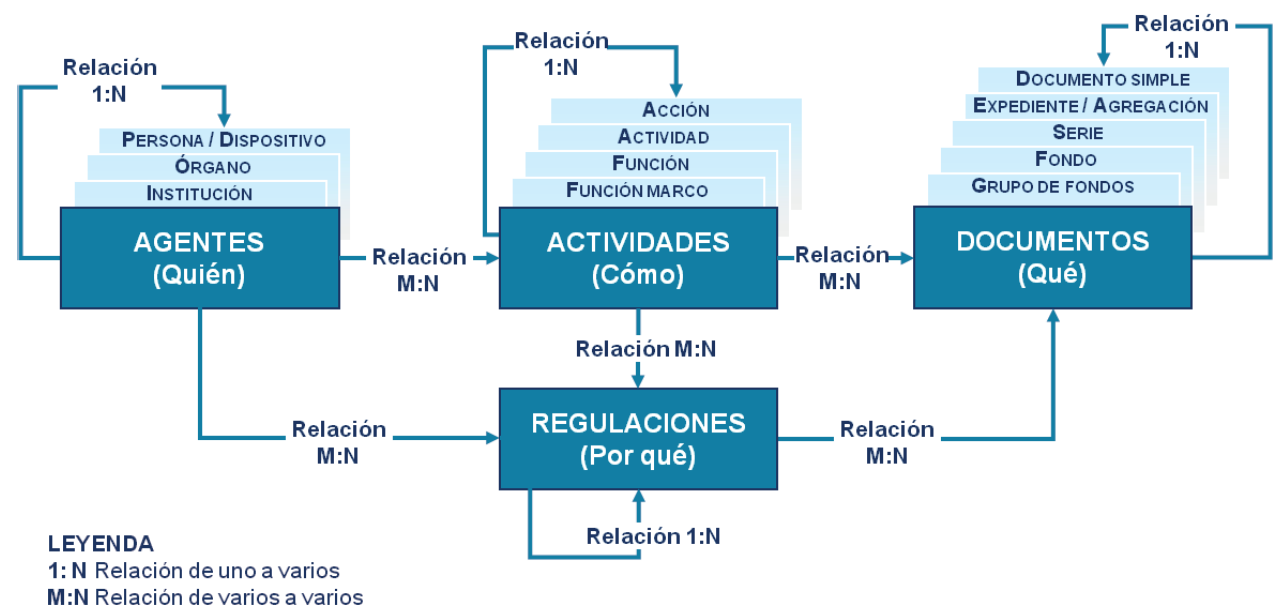

1. Multi-entidad. El Documento, el Agente, la Regulación, la Actividad y la Relación son las distintas entidades que inciden en los metadatos de los documentos. Los documentos se crean porque existen vínculos entre estas entidades.

2. Uso de relación y eventos. Para indicar el contexto de los documentos. La Relación describe los eventos que se producen por su capacidad de vincular dos o más entidades, registra información de los eventos a medida que se suceden y sin que puedan ser modificados en los elementos Fecha, Nombre, Entidad Relacionada, Trazabilidad.

3. Especificaciones de uso de los metadatos. Si son obligatorios, condicionales u opcionales.

4. Aplicación de un esquema de valores de metadatos que pueden ser opcionales u obligatorios, según decida el personal responsable.

Con los datos que cada metadato va recabando en un contexto, momento y evento concreto a causa de una relación entre las entidades, se genera una información genuina, contextualizada e inequívoca, singular de cada metadato y dentro de un documento o grupo de documentos, convirtiendo a estos metadatos en elementos de validación sólidos y exhaustivos de los e-Docs. 
El metadato, como recoge Pérez Palací (2014: p. 17-18), puede ser considerado con el rango de evidencia jurídica o prueba electrónica incorporable a un juicio dentro de las pruebas documentales. Pues, como pruebas documentales, estos e-Docs. tienen, efectivamente, unos metadatos mínimos que los hacen ser considerados como plenos, auténticos, íntegros y fiables, y no como entidades incompletas. Estos metadatos mínimos se han fijado en una Resolución de 19 de julio de 2011 de la Secretaría de Estado para la Función Pública, aprobando la NTI del e-Doc., más tarde desarrollada en la segunda edición de la Guía de Aplicación de la Norma Técnica de Interoperabilidad (julio 2016) que establece y define los elementos que componen el e-Doc. En su anexo I, considera los siguientes metadatos mínimos, aparte de los complementarios que cada entidad estime añadir conforme a sus necesidades:

1. Versión NTI. Identifica en una URI la versión de la Norma Técnica de Interoperabilidad que estructura el e-Doc.

2. Identificador. Identificador normalizado del documento en una cadena de caracteres.

3. Órgano. Identificador normalizado del organismo que captura o genera el documento en una cadena de caracteres.

4. Fecha de Captura. Fecha de alta en el SGD en un campo fecha y hora.

5. Origen. Indica si el documento lo ha creado un ciudadano o una administración.

6. Estado de Elaboración. Indica en una cadena de caracteres la naturaleza del documento desde el punto de vista de su tradición, es decir, si es original, copia electrónica auténtica con cambio de formato o de documento papel, copia electrónica parcial auténtica, etc.

7. Nombre del Formato. Expresa el formato lógico del fichero de contenido del e-Doc. a través de una cadena de caracteres.

8. Tipo Documental. Describe mediante otra cadena de caracteres, desde la Diplomática, la tipología del documento.

9. Tipo de Firma. Precisa qué firma avala el documento también en una cadena de caracteres. Si es la firma un Código Seguro de Verificación (CSV) se añaden:

- El Valor del CSV, expresada con una cadena de caracteres.

- La Definición de Generación del CSV. Refiere la orden, resolución o documento que define la creación del CSV correspondiente en una cadena de caracteres. 
10. Identificador de Documento Origen. En cuanto al estado de elaboración de las copias, lleva en otra cadena de caracteres la identificación normalizada del documento original al que se corresponde la copia.

Ante lo enunciado por el legislador, podríamos preguntarnos cuál es la praxis y la realidad del día a día respecto a lo articulado sobre este asunto. Para ello nos vamos a remitir al Tribunal Supremo (TS), en algunas de cuyas sentencias entran en juego el valor de los metadatos en nuestra vida diaria. Pues debemos entender que cualquier documento, tanto público como privado, tiene como potencial destinatario final o cliente último una instancia superior competente que entienda de los asuntos en litigio que atañen al documento, sea electrónico o tradicional, y que vienen siendo habitualmente los jueces miembros de un tribunal que son quienes, en última instancia, admiten o rechazan su integridad y su autenticidad indubitada.

Podríamos traer a colación varias sentencias, pero comentaremos muy brevemente el sí contenido de dos dictadas por el Alto Tribunal. La primera es la 1551/2018, de la Sala de lo Penal, en donde los miembros del tribunal dan por bueno la información recogida en los metadatos, apoyándose en los mismos para fundamentar hechos y actuaciones sobre los documentos, en una secuencia concreta con la intervención de diversos actores ${ }^{9}$. Dichos metadatos valorados en la sentencia podían ser tales como Fecha de Creación, Creado Modificado, Última Modificación y, por supuesto, Firma Electrónica.

La segunda sentencia es la 2025/2018, del mismo Tribunal Supremo, Sala de lo Civil, donde se dice que un documento no se encuentra validado por uno de sus autores a falta de firma manual o electrónica, sancionando la plena equiparación legal de la firma manuscrita, para los documentos clásicos, con la firma electrónica avanzada, para los documentos digitales ${ }^{10}$.

Vemos, por tanto, que lo definido por el legislador es de plena aplicación práctica en la vida real. Los metadatos no solo han venido para resolver la autenticidad de los documentos electrónicos, sino que son, en sí mismos, pruebas presentables en juicios (véase Pérez Palací, 2014, p. 3) ${ }^{11}$.

9 Sentencia TS 1551/2018.

10 Sentencia TS 2025/2018.

11 Como resume Pérez Palací, los medios de prueba están recogidos en el artículo 299 de la Ley de Enjuiciamiento Civil, clasificados en tres grupos: los clásicos o tradicionales, caso de los interrogatorios de las partes, documentos públicos y privados, dictamen de peritos, reconocimiento judicial e interrogatorio de testigos (299.1); los modernos o actuales, como audiovisuales e instrumentos informáticos (299.2) y medios futuros, cerrando con una cláusula abierta que incorpora todos aquellos medios probatorios desconocidos en la actualidad (299.3). 
Los metadatos mínimos posibilitan la existencia del documento como tal ya que nos lo encuadra en una tipología, en un autor o autores, en el tiempo, en su contenido $\mathrm{y}$ en las normas que rigen su existencia.

Por el contrario, los metadatos complementarios nos pueden ayudar a conocer su momento en la gestión documental, su tradición o diversos modos de transmisión del propio documento, su situación dentro de un proceso o procedimiento, e incluso si se trata de un documento simple o de un documento entrelazado con otros documentos formando parte de un expediente. Es decir, los metadatos nos permiten disponer de la trazabilidad de la permanencia y conservación del e-Doc. siempre y cuando dispongamos de una Política de Gestión de Documentos Electrónicos (PGDE) en la que se recojan y ejecuten los procedimientos concretos para el copiado auténtico de los documentos electrónicos (véase Cortés Ruiz, 2017) que nos permitan su migración y conservación en el tiempo (BOE 182, de 30/7/2011-NTI, PGDE del Ministerio de Hacienda y Administraciones Públicas, 2016: p. 53 y PGDE del Ministerio de Defensa, 2017: pp. 68-70 y anexo I), así como disponer en todo momento, a pesar del tiempo transcurrido, de documentos completos, accesibles, auténticos, procesables y potencialmente reutilizables (véase CIA, 2006).

Los metadatos mínimos, más los complementarios que se estimen por cada entidad, sirven para dotar a los e-Docs. de la autenticidad, disponibilidad e integridad que les posibilita cumplir con sus funciones de dar testimonio fehaciente de gestiones, obligaciones, hechos y derechos, además de convertirlos en pruebas electrónicas fiables. De ese modo los e-Docs., como sus antecesores en soporte papel, son el arsenal jurídico de las correspondientes entidades titulares.

\section{CONGLUSIONES}

Hoy, como ayer, el documento se ha rodeado de una serie de fórmulas y mecanismos para garantizar su autenticidad y ser un instrumento no solo de información sino también de garantía de derechos.

Como ha quedado aquí puesto de manifiesto, los metadatos contribuyen a garantizar la autenticidad, fiabilidad e integridad de los nuevos documentos electrónicos, en cumplimiento de la norma UNE-ISO 23081-1. Esta garantía se configura con una serie de elementos como la firma electrónica avanzada, basada en un certificado reconocido y generada mediante un dispositivo seguro que "tendrá respecto de los datos consignados en forma electrónica el mismo valor que la firma manuscrita en relación con los consignados en papel" (artículo 3.4. de la Ley 59/2003 de Firma Electrónica).

Es interesante destacar en este punto el desarrollo por distintas entidades de sus propios esquemas de metadatos y de políticas de gestión de documentos electrónicos para asegurar, por medio de su distribución, la generación y gestión homogénea de sus documentos electrónicos, así como para generar la debida trazabilidad en las migraciones, cambios de formatos y de soportes en los que se encuentre los documentos 
que nos permitan su conservación a lo largo del tiempo, preservando igualmente su accesibilidad, integridad y autenticidad.

Pero también la autenticidad e integridad del e-Doc. viene dada por la misma naturaleza de los documentos ya que estos, como los de soporte en papel, funcionan como sistemas irreductiblemente complejos, tanto en el caso de las unidades simples como de los documentos entrelazados de los expedientes o dossiers, siguiendo a Michael J. Behe, que creó dicho concepto refiriéndolo como "un sistema individual compuesto de varias partes bien coordinadas que interaccionan para desempeñar la función básica de este, de modo que si se eliminara cualquiera de esas partes el sistema dejaría de funcionar por completo" (Behe, 2000 , p. 39). En otras palabras, un sistema irreducible es el nivel más sencillo en el que puede funcionar dicho sistema.

Dichas partes las hemos estado identificando a lo largo del artículo como los elementos de validación, tanto en los documentos en entornos tradicionales como en entornos digitales. Las interacciones de esas partes dotan a los documentos de integridad, autenticidad, salvaguarda de derechos y obligaciones, así como testimonio fiel de actividades de individuos o entidades.

Igualmente, estas partes en los entornos digitales no han supuesto una degradación o cambio de las características intrínsecas de los documentos, sino más bien han contribuido a realizar una transición segura, sin sobresaltos y enriquecedora desde el soporte papel al nuevo entorno tecnológico.

A raíz de esto, por lo que se refleja en las políticas de gestión de los documentos electrónicos y sus esquemas de metadatos, podemos también considerar los documentos como sistemas complejos, pero dotados de agentes y componentes que interactúan entre ellos, entrelazándose y autogestionándose, con diferentes roles o comportamientos según el entorno en el que se encuentren o cuando se vean sometidos a diferentes interacciones.

Estos agentes y componentes, a los que llamamos de forma genérica nódulos, se encuentran interactuando, como hemos dicho, por medio de diferentes conexiones o relaciones, aunque no de forma homogénea ya que por lo general nos encontraremos unos pocos nódulos, que a su vez podríamos llamar nódulos primarios, en los que se concentran muchas más conexiones, mientras que en el resto se establecen proporcionalmente un número reducido de estas relaciones. En la incorporación de nuevos nódulos al documento, es más factible que se establezcan gran parte de sus relaciones con estos nódulos primarios que con el resto.

En definitiva, podríamos concebir la estructura de los documentos como propia de sistemas complejos, formados por nódulos multifuncionales que interactúan entre sí de diferente forma por medio de relaciones que los conectan, según el entorno en el que se encuentren, unas conexiones distribuidas entre los nódulos que los forman de manera no homogénea o simétrica (Fig. 6). 


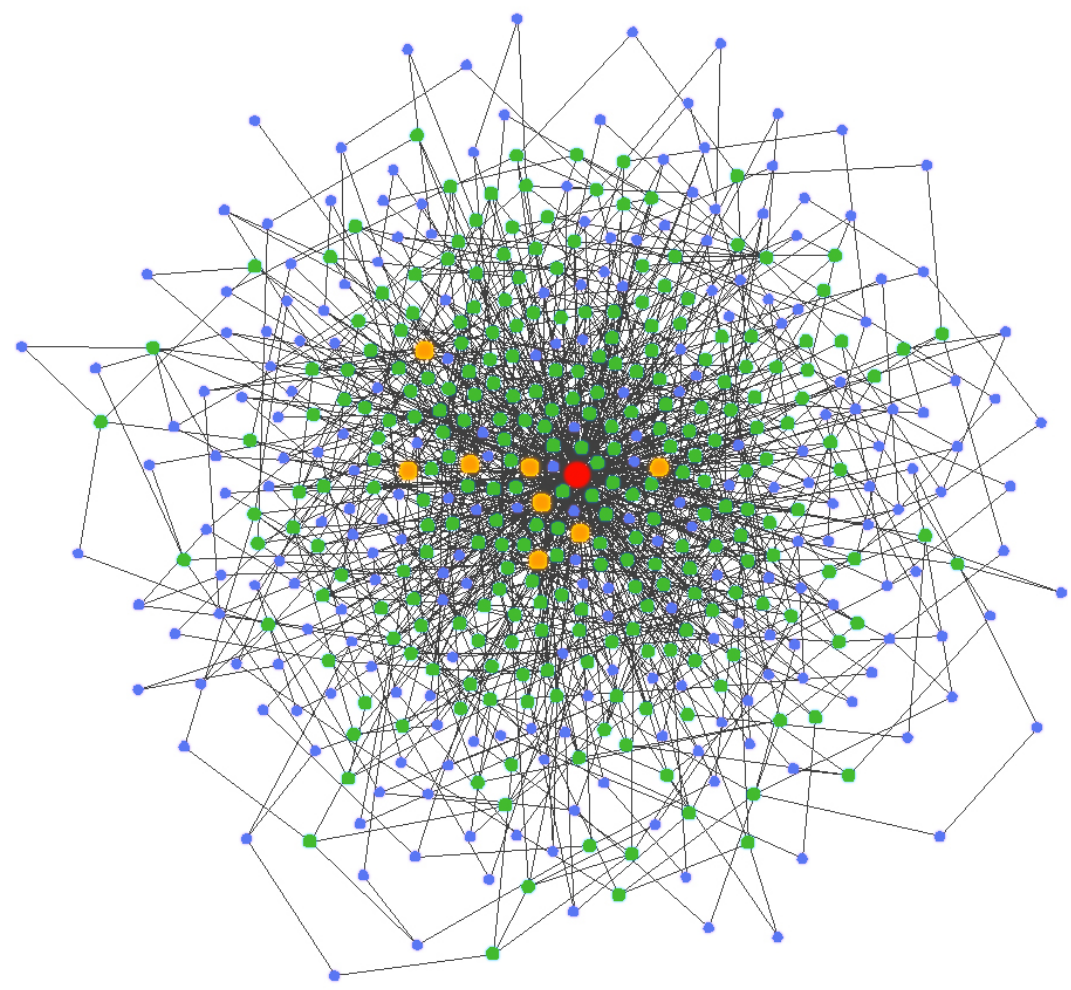

Figura 6. Esquema de sistemas complejos. Fuente: https://apascuasj.files.wordpress.com/2011/02/sistemas-complejos.jpg?w $=450$ [consulta 14/06/2020]

\section{BIBLIOGRAFÍA}

Álvarez Ceruela, José María (1957). Signos y firmas reales. Con extractos biográficos de los monarcas españoles del siglo VIII al XX. Santiago de Compostela: La Comercial.

Arribas Arranz, Filemón (1941). Sellos de placa de las cancillerías regias castellanas. Valladolid: Talleres Tipográficos Cuesta.

Bascapé, Giacomo Carlo (1969-1984). Sigillografia: il sigillo nella diplomatica, nel diritto, nella storia, nell’arte, 3 vols. Milán: A. Giuffre.

Behe, Michael J. (2000). La caja negra de Darwin: el reto de la bioquímica a la evolución. Barcelona: Andrés Bello.

BOE 182, de 30/7/2011, Resolución de 19 de julio de 2011, de la Secretaría de Estado para la Función Pública, por la que se aprueba la Norma Técnica de Interoperabilidad de Documento Electrónico, pp. 87094-87107. 
BOE 178, de 26/7/2012, Resolución de 28 de junio de 2012, de la Secretaría de Estado de Administraciones Públicas, por la que se aprueba la Norma Técnica de Interoperabilidad de Política de gestión de documentos electrónicos, pp. 53776-53780.

Bono Huerta, José (1990). Breve Introducción a la Diplomática Notarial Española, vol. 1. Sevilla: Junta de Andalucía, Consejería de Cultura y Medio Ambiente.

Boüard, Alain de (1929). Manuel de Diplomatique Française et Pontificale. Diplomatique générale. 2 vols. Paris: Auguste Picard.

Bresslau, Harry (1889-1931). Handbuch der Urkundenlehre für Deutschland und Italien, 2 vols, Leipzig.

Bustos Pretel, Gerardo (coord.) (2018). La gestión del documento electrónico. Madrid: Wolters Kluwer.

Canellas López, Ángel (ed.) (1991). Falsos y falsificaciones de documentos diplomáticos en la Edad Media. Zaragoza.

Carmona de los Santos, María (1996). Manual de Sigilografía. Madrid: Subdirección Estatal de los Archivos Estatales.

Caruana, Jaime (1955). Los confirmantes en documentos de Alfonso II. Revista Archivos, Bibliotecas y Museos, 61, pp. 5-22.

Casado de Otaola, Luis (1997). Per visibilia ad invisibilia: Representaciones figurativas en documentos altomedievales como símbolos de validación y autoría. Signo, 4, pp. 39-56.

CIA: Consejo Internacional de Archivos (2006). Documentos Electrónicos: Manual para archiveros. Madrid: Ministerio de Cultura; Subdirección de Publicaciones, Información y Documentación.

Disponible en: http://www.mcu.es/ccbae/es/consulta/registro.cmd?id=213949 [Consulta: 4 de febrero de 2021].

Cortés Ruiz, Elena (2017). La política de gestión de documentos electrónicos del Ministerio de Educación, Cultura y Deporte. Tria, 21, pp. 121-133.

Díaz Rodríguez, Alfonso (2007). El concepto de documento electrónico y su validación, en Remedios Rey de las Peñas (coord.): La validación de los documentos: pasado, presente y futuro. VIII Jornadas Archivísticas. Huelva: Diputación Provincial de Huelva, pp. 133-142.

Eisenlohr, Erika (1994). Monogramme und Invokationszeichen in iberischen und fräne kischen Urkunden. Signo, 1, pp. 35-50.

Fichtenau, Heinrich (1979). Die Reihung der Zeugen in Urkunden des frühen Mittelalters, en Paleographica, Diplomatica et Archivistica. Studi in onore di G. Battelli, vol. II, Roma, pp. 41-59.

Francisco Olmos, José María de (2017). El signo rodado regio en España. Orígenes y desarrollo. Madrid: Real Academia Matritense de Heráldica y Genealogía. 
Diplomática y e-Diplomática...- A. Sánchez González y D. de la Prada Espina

Fraenkel, Béatrice (1992). La signature. Genèse d’un signe. Paris: Gallimard.

Galende Díaz, Juan Carlos (1996). Un sistema de validación documental: de la quirografía a las cartas partidas. Espacio, Tiempo y Forma. Serie III, Historia Medieval, 9, pp. 347-381. DOI: https://doi.org/10.5944/etfiii.9.1996.3598

García Fernández, Manuel y Sánchez González, Antonio (2020). Documentos medievales de la Colección Salazar y Castro en la Real Academia de la Historia de España: Estudio de los privilegios rodados. Intus-Legere Historia, vol. 14, 2, pp. 124-150. DOI: https://doi.org/10.15691/\%25x

García García, Francisco de Asís (2010). El crismón. Revista Digital de Iconografía Medieval, vol. II, n 3, pp. 21-31.

Giry, Arthur (1975). Manuel de Diplomatique. Genève: Slaktine, 1975 (reed. de la ed. de Paris, 1894).

Gómez Flores, Sergio (2015). Metadatos y Gestión Documental. Disponible en: https:// www.archivoz.es/archivo-electronico-metadatos-la-gestion-documental/ [Consulta: 30 de marzo de 2020].

ICA: International Council on Archives- (2011a). Guide for Managing Electronic Records from an Archival Perspective, Study 8. Disponible en: https://www.ica.org/es/ node/15379 [Consulta: 21 de mayo de 2020].

ICA: International Council on Archives- (2011b). Manual de documentos electrónice os, Study 16. Disponible en: www.ica.org > ICA_Study-16-Electronic-records_ES [Consulta: 21 de mayo de 2020].

Kittel, Erich (1970). Siegel. Braunschweig: Klinkhardt u. Biermann.

Laurent, R. (1985). Sigillographie. Bruselas: Archives Générales du Royaume.

Legipont, Oliver (1759). Itinerario en que se contiene el modo de hacer con utilidad los Viajes a Cortes extranjeras, con dos Disertaciones. La primera sobre el modo de ordenar y componer una Libraria [sic. = Biblioteca]. La segunda sobre el modo de poner en orden un Archivo. Obra traducida del latín al español por el doctor Joaquín Marín. Valencia: por Benito Monfort, 1759 [Ejemplar en el AHN de Madrid].

Ley 1/2000, de 7 de enero, de Enjuiciamiento Civil. BOE 7, de 08/01/2000.

Ley 59/2003, de 19 de diciembre, de Firma Electrónica. BOE 304, de 20/12/2003.

Linage Conde, Antonio (1970). Las suscripciones de los escribas en el alto medievo peninsular. Revista de Derecho Notarial, 69-70, pp. 205-231.

Martín López, María Encarnación (1994-1995). La carta partida como forma de validación. Estudis castellonencs, 6, pp. 839-856.

Mendo Carmona, Concepción (1997). La suscripción altomedieval. Signo, 4, pp. 207-229.

Menéndez Pidal de Navascués, Faustino (1993). Apuntes de Sigilografía española. Guadalajara: Aache. 
Menéndez Pidal de Navascués, Faustino (2018). Los sellos en nuestra historia. Madrid: Boletín Oficial del Estado y Real Academia de la Historia.

Ministerio de Defensa (2017). Política de Gestión de los Documentos Electrónicos del Ministerio de Defensa. Madrid. Disponible en: https://publicaciones.defensa.gob.es/fileuploader/download/download/?d=0\&file=custom\%2Fupload\%2FFile- 1508931174 . pdf [Consulta: 4 de febrero de 2021].

Ministerio de Hacienda y Administraciones Públicas. Secretaría General Técnica (2016). Guía de Aplicación de la Norma Técnica de interoperabilidad de la Política de Gestión de los Documentos Electrónicos. 2a ed. Madrid.

Ministerio de Política Territorial y Función Pública. Secretaría de Estado de la Función Pública (2016). Nueva versión del Esquema de Metadatos para la Gestión del Documento Electrónico (e-EMGDE v2.0). Madrid.

Moreq 2 (2016): Model Requirements for the Management of Electronic Records. Disi ponible en: http://cornwell.co.uk/moreq [Consulta: 30 de marzo de 2020].

Ouy, Gilbert (1961). Les faux dans les Archives et les Bibliothèques, en Ch. Samaran (dir.), L'histoire et ses méthodes. Paris: Gallimard, pp. 1367-1383.

Pardo Rodríguez, María Luisa (1999). La Rueda Hispana. Validación y Simbología, en Peter Herde y Hermann Jakobs (eds.): Papsturkunde und europäisches Urkundenwesen. Colonia-Weimar-Viena, pp. 241-255.

Pastoureau, Michel (1981). Les sceaux. Turnhout: Brepols.

Pérez-Aínsua Méndez, Natalia (2014). De sellos, heráldica y alegorías: el papel sellado en España. Sevilla: Universidad de Sevilla.

Pérez Palací, José Enrique (2014). La prueba Electrónica: Consideraciones. Universitat Oberta de Catalunya, 2014. Disponible en:

http://openaccess.uoc.edu/webapps/o2/bitstream/10609/39084/1/PruebaElectronica2014.pdf [Consulta: 1 de abril de 2020].

Real Decreto 4/2010, de 8 de enero, por el que se regula el Esquema Nacional de Interoperabilidad en el ámbito de la Administración Electrónica. BOE 25, de 29/1/2010, pp. 8139-8156.

Redondo Herranz, María de Hontanares (2010). El documento electrónico: un enfoque archivístico. Revista General de Información y Documentación, 20, pp. 391-408. Disponible en:

https://revistas.ucm.es/index.php/RGID/article/viewFile/RGID1010110391A/9090 [Consulta: 1 de abril de 2020].

Riesco Terrero, Ángel (2003). Vocabulario Científico-Técnico de Paleografía, Diplomática y Ciencias Afines. Madrid: Barrero\&Azedo.

Rück, Peter (ed.) (1996). Graphische Symbole in mittelalterlichen Urkunden. Beiträge zur diplomatischen Semiotik. Sigmaringen: Jan Thorbecke. 
Diplomática y e-Diplomática...- A. Sánchez González y D. de la Prada Espina

Sánchez González, Antonio (2012). Los privilegios rodados originales del Archivo Ducal de Medinaceli: I. Alfonso VIII de Castilla (1158-1214). En la España Medieval, 35, pp. 367-412. DOI: http://dx.doi.org/10.5209/rev_ELEM.2012.v35.39041

UNE-ISO 15489-1 (2016). Información y documentación. Gestión de documentos. Parte 1: Conceptos y principios. Disponible en: https://www.aenor.com/normas-y-libros/ buscador-de-normas/une?c=N0057440 [Consulta: 30 de marzo de 2020].

UNE-ISO 23081-1 (2018). Información y documentación. Procesos de gestión de documentos. Metadatos para la gestión de documentos. Disponible en: https://www.aenor.com/normas-y-libros/buscador-de-normas/UNE?c=N0059599 [Consulta: 30 de marzo de 2020].

Valls Subirá, Oriol (1962). El signum notarial. Barcelona: Junta de Decanos de los Colegios Notariales de España. Centenario de la Ley del Notariado, vol. II, tomo II. 